\title{
The enigma of gigantism: effect of larval trematodes on growth, fecundity, egestion and locomotion in Hydrobia ulvae (Pennant) (Gastropoda:Prosobranchia)
}

\author{
Kim N. Mouritsen*, K. Thomas Jensen \\ Department of Ecology and Genetics, Institute of Biological Sciences, Univerity of Aarhus. DK-8000 \\ Aarhus C, Denmark
}

Received 20 October 1993; revision received 15 February 1994; accepted 25 March 1994

\begin{abstract}
The effect of larval trematodes on growth, fecundity, egestion and locomotor activity in naturally infected Hydrobia ulvae (Pennant) was studied in the laboratory. Infected snails showed increased growth rates (shell height, body wet weight) compared with uninfected controls. $\mathrm{C} / \mathrm{N}$ analysis of the snails suggested that the additional growth of infected specimens included shell material as well as dry soft tissue. Infection caused a significant reduction in penis size and an almost complete cessation of oviposition. As judged by their egestion rates, food consumption rates of infected and uninfected snails were roughly similar, but infection caused a significant reduction in locomotor activity. It is suggested that the energetic basis for parasite metabolism and excess host growth is in part reallocated reproductive energy following castration, and in part energy saved by reduced locomotor activity.

Some previously reported hypotheses explaining the equivocal evidence on parasite-induced growth cnhancement are discussed. It is argued that the phenomenon is not necessarily speciesspecific, but should also be addressed at the level of subpopulations both in and outside the snails" reproductive season.
\end{abstract}

Keyuords: Egestion; Fecundity; Growth; Hydrobia ulvae; Locomotion; Trematodes

\section{Introduction}

Since Wesenberg-Lund (1934) noted that trematode infected snails attained a larger size than uninfected specimens, several studies have been devoted to this phenomenon, termed gigantism. However, no general consensus has yet emerged regarding the effect

\footnotetext{
* Corresponding author.
} 
of parasites on snail growth. Some studies have provided evidence for an accelerated growth rate in parasitized snail specimens (Rothschild \& Rothschild, 1939; McClelland \& Bourns, 1969; Meuleman, 1972; Sluiters et al., 1980; Wilson \& Denison, 1980), whereas others have reported no or stunting effects of trematode infections (Moose, 1963; Sturrock \& Sturrock, 1970; Sousa, 1983; Crews \& Yoshing, 1989; Fernandez. \& Esch, 1991a; Huxham et al., 1993).

Besides indications that the life history of the snail host, as well as the species of trematode, affect growth rate following infection (e.g. Sousa, 1983; Minchella, 1985), the ambiguous evidence might in part be assigned to methodological problems. Recently, Fernandez \& Esch (1991a) have even questioned gigantism as a naturally occurring phenomenon, and instead have ascribed it to laboratory artifact. Moreover, application of different measures for snail growth (shell size, wet weight, dry tissue weight etc.) in different studies may have produced conflicting results and conclusions. In this respect, two studies have demonstrated that parasite-induced size increment not necessarily involves all parts of the snail. Cheng (1971), working with two different host-parasite associations, reported that the increased size of infected snails was due to increased shell size rather than to an increase in soft tissue growth. Similar results were obtained by Joosse \& Van Elk (1986), showing that the dry tissue weight of infected and uninfected Lymnaea stagnalis did not differ, whereas total body weight and shell weight were disproportionally large in infected individuals. Although rarely studied, the effect of infection on food consumption and locomotor activity may also be expected to influence the growth pattern of the host. Parasite-mediated consumption has been shown to differ between even closely related hosts (sensu Meuleman, 1972; Williams \& Gilbertson, 1983), and indirect evidence for energy saving through reduced crawling in infected snails has been provided by Becker (1980a,b).

So far, parasite-induced growth enhancement has not been demonstrated in marine gastropods, the exception being Hydrobia ulvae (Pennant). Considering the equivocal information on the issue, the purpose of the present study was to revisit Rothschild and Rothschild's (1939) pioneering laboratory research on $H$. ulvae by using recent data analysis, and further extend the work regarding the effect of parasites on host fecundity, egestion and locomotor activity. The hypothesis that parasite-induced growth increment does not involve the dry soft tissue of the snail is tested.

\section{Materials and methods}

\subsection{Collection of animals}

Unbiased samples of the H. ulvae population at Højer tidal flat in the Danish Wadden Sea $\left(54^{\circ} 56^{\prime} \mathrm{N}, 8^{\circ} 39^{\prime} \mathrm{E}\right)$ were collected in April 1991 (Experiment I) and September 1992 (Experiments II and III). The population of $H$. ulvae exhibit a high prevalence of larval digenetic trematodes in this area (Jensen \& Mouritsen, 1992). The snails collected in April were just beginning to reproduce, as indicated by the presence of only few egg-capsules on their shells. The animals were brought to the laboratory and acclimated in storage tanks under experimental conditions prior to commencement of the experiments. 


\subsection{Preparation of snail food}

Surface sediment collected in situ during each of the two sampling occasions was sieved in seawater through a $63 \mu \mathrm{m}$ screen. The silt fraction $(<63 \mu \mathrm{m})$ was then left at $20^{\circ} \mathrm{C}$ on a window sill in storage tanks supplied with seawater, and used as substrate and food supply for the snails throughout the experiments. The silt fraction was rich in epipelic diatoms that are important food items for hydrobiids (Jensen \& Siegismund, 1980).

\subsection{Experiment I: fecundity, growth and egestion rates}

One hundred individuals were chosen randomly for further experimental treatment. The snails' shell height (apex to aperture) and wet weight were measured to the nearest $0.1 \mathrm{~mm}$ and $0.1 \mathrm{mg}$, respectively. Before weighing the animals were dried briefly on blotting paper, and algae as well as egg-capsules were removed from the shell. The snails were then transferred individually to $22 \mathrm{ml}$ containers $(4 \times 5.5 \times 1.0 \mathrm{~cm})$ supplied with $28 \%$ seawater and $2 \mathrm{ml}$ sediment. The snails were left at constant temperature $\left(14 \pm 1^{\circ} \mathrm{C}\right)$ and $24-\mathrm{h}$ illumination for 42 days. During the experiment, water and sediment were replaced weekly, at which time also the egg-capsules deposited in the containers were counted and subsequently removed. During replacement of the sediment, old substrate from each container was sieved through a $75 \mu \mathrm{m}$ screen in $28 \%$ seawater in order to separate faecal pellets from uneaten sediment. The faeces fraction was transferred to pre-dried and pre-weighed glass microfibre filters. Filters and faeces were oven-dried at $65^{\circ} \mathrm{C}$ for $20 \mathrm{~h}$, and the dry weight measured to the nearest $0.1 \mathrm{mg}$. From these data the weekly production of faecal pellets of each specimen was determined.

At the end of the experiment each snail was dried briefly on blotting paper, algae were removed from the shell, and the snail's total body wet weight was measured prior to individual fixation in $10 \%$ buffered formalin. Later, shell height was measured and the animals were subsequently dissected under stereomicroscope. Species of trematodes were identified according to Deblock (1980). Snail gender was determined, and penis size was estimated by measuring the length and width (at base).

\subsection{Experiment II: growth and $C / N$ composition}

An additional growth experiment was carried out in the laboratory from October 1992 to January 1993 in order to (1) determine possible differences between the growth rate of infected and uninfected snails collected outside their natural reproductive season, and (2) determine if increased growth of infected snails was caused by shell growth only. Eighteen pairs of snails, each pair composed of one infected (shedding echinostomide or microphallide cercariae) and one uninfected control specimen (not shedding cercariae) of similar shell height $(1 / 16 \mathrm{~mm}$ accuracy), were established individually in containers (radius $=27 \mathrm{~mm}, 23 \mathrm{ml}$ ) supplied with $28 \%$ seawater and $2 \mathrm{ml}$ sediment. The snails were left under conditions similar to those in Experiment I for 85 days. Once a week, water and sediment were replaced and the containers were inspected for the presence of egg-capsules. On four occasions during the experiment, all 36 snails were 
transferred to containers supplied with $28 \%$ seawater only. After $24 \mathrm{~h}$ under experimental conditions the containers were inspected under a stereomicroscope for the presence of emerged cercariae to confirm shedding among the infected individuals and to reveal possible false negative controls. Although dissection may be the only accurate method for identification of uninfected specimens (Curtis \& Hubbard, 1990), the present approach is the best alternative if the snails has to be kept alive. The proportion of snails infected with metacercariae that could not be detected by this procedure was negligible in the collected $H$. ulvae population $(<3 \%)$. Since parasitized males usually possess a small penis (see Results), only males with normal-sized penis was used, further minimizing the probability of infections among control individuals. At the end of the experiment the snails' shell height and total body wet weight were measured. Before weighing, the animals were dried on blotting paper and algae removed from the shell. The snails were then dried for 4 days at $70^{\circ} \mathrm{C}$, transferred to a desiccator to cool, and reweighed to obtain total body dry weight. Finally, the $\mathrm{C} / \mathrm{N}$ composition $(\% / \%)$ and the total $\mathrm{N}$ content $(\mathrm{mol} / \mathrm{g}$ ) of the dried specimens were determined in a Carlo Erba, NA $1500, \mathrm{C} / \mathrm{N}$ analyzer.

The $\mathrm{C} / \mathrm{N}$ analysis was applied as an alternative method for weight measurements of the shell and soft tissue separately. The latter measurements would be inaccurate due to the small size of the snails. Because of the high $\mathrm{CaCO}_{3}$ content in shells, however, the $\mathrm{C} / \mathrm{N}$ ratios of shells and soft parts were expected to be very different. Disproportional growth between shell and soft tissue in infected animals compared with uninfected snails should therefore be detectable by a $\mathrm{C} / \mathrm{N}$ analysis. In order to test this expectation, 10 pairs of snails [all $4.1-4.5 \mathrm{~mm}$ in shell height but pair-wise of identical height ( $1 / 16 \mathrm{~mm}$ accuracy)], and 10 snails with $4.5-6.7 \%$ larger shell heights than the former 10 pairs, were dissected, and shell and soft tissue were separated. The shell and soft parts of the first 10 smaller specimens were rejoined, whereas the soft parts of the last 10 small snails were pooled together with the shells from the larger individuals. The resulting 10 paired samples were dried for 4 days at $70^{\circ} \mathrm{C}$, transferred to a desiccator to cool, and then analyzed for their $\mathrm{C} / \mathrm{N}$ composition. The results showed a significant higher mean $\mathrm{C} / \mathrm{N}$ ratio among snails with experimentally enlarged shells (17.0) compared with controls specimens with their natural shells (15.0, two-tailed signed rank test, $p<0.04$ ). This demonstrates that the $\mathrm{C} / \mathrm{N}$ analysis is a suitable method for detection of small disproportional increases of shells and soft parts.

\subsection{Experiment III: locomotor activity}

A preliminary quantification of the number of crawling/feeding tracks made by the snails on the sediment surface one hour after commencement of Experiment I suggested reduced locomotor activity among infected snails. In order to verify this observation, 40 microphallide infected (Maritrema subdolum and Microphallus claviformis and 42 echinostomide infected (Himasthla continua) as well as 38 uninfected snails were established under conditions similar to those in Experiment II. After $24 \mathrm{~h}$, the snails were carefully removed from the water, and the containers were shaken lightly in order to erase old trails. When the sediment had settled after about $10 \mathrm{~s}$, the snails were released in the centre of the containers. During the following $1.5 \mathrm{~h}$, the snails' position and trail 
pattern were mapped every 10 th min. Hereafter, the mapped trails was measured to the nearest $\mathrm{mm}$, and the average crawling velocity $(\mathrm{cm} / \mathrm{min})$ during the $1.5 \mathrm{~h}$ observation period were calculated for each snail specimen. The mean shell height of the three groups of snails used did not differ (One-way ANOVA, $F_{2,119}=1.28, p=0.28$ ). Considered together the average shell height was $4.7 \mathrm{~mm}(\mathrm{SD}=0.5$; range $=3.4-5.9 \mathrm{~mm}$; $n=120$ ). Since infection may enhance growth (see Results), the infected snails could be younger than the uninfected. However, the experimental individuals were collected in September and belonged to one cohort (1-group) discernible by size from the younger cohort ( 0 -group) that had settled about 2 months earlier. Albeit individuals from the zero group might have been infected immediately after settling they could not have obtained the size of the used snails.

The type of infection was established by identification of emerged cercariae. Uninfected control snails were dissected posteriori to the observations in order to sort out false negative controls and determine the gender of the snails.

\subsection{Data analysis}

Preliminary data analysis revealed that Gompertz plots of snail growth, describing the specific growth rate $\ln \left(S_{2} / S_{1}\right) / t$ versus $\ln S_{1}\left(S_{1}\right.$ and $S_{2}$ are initial and final size during the time interval $t$ ), resulted in the highest correlation coefficient in comparison with other commonly applied growth curves (see Kaufmann, 1981). Hence, this approach was used for describing the growth in terms of shell height and body wet weight increment of infected and uninfected $H$. ulvae from Experiment I.

Statistical analyses (parametric tests) were performed using SPSS (Hull \& Nie, 1981). A test for homogeneity of variance was carried out prior to all analysis of variance and $t$-tests. In a single case the data did not meet the assumption of homogeneity of variance $(0.01<p<0.05)$. Consequently, the level of significance was tightened by choosing $1 \%$ rather than the default $5 \%$ in the main analysis (sensu Underwood, 1981).

\section{Results}

\subsection{Fecundity, growth and egestion rates}

Of the 100 snails selected for the experiment 94 survived. Of these, 30 specimens $(32 \%)$ were infected by one of five different species of digenic trematodes (Table 1 ).

Table 1

Frequency of trematode species in $H$. ulvae from Experiment I

\begin{tabular}{lll}
\hline Family & Species & Number \\
\hline Microphallidae & Maritrema subdolum & 7 \\
& Microphallus claviformis & 4 \\
& Cercaria? (Levinseniella) & 2 \\
Heterophyidae & Cryptocotyle concava & 6 \\
Echinostomatidae & Himasthla continua & 11 \\
\hline
\end{tabular}




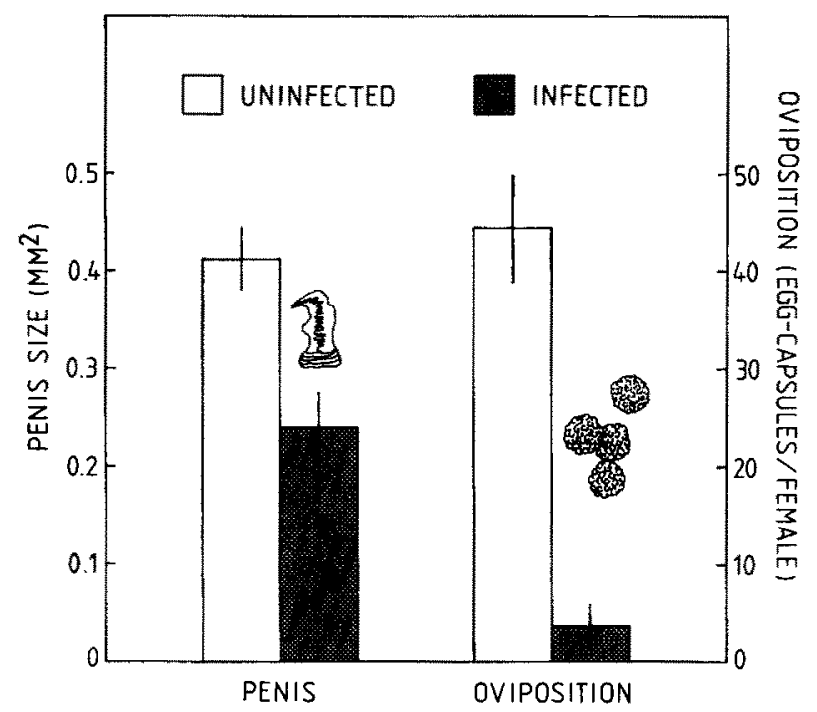

Fig. 1. Average penis size $\left(\mathrm{mm}^{2}+\mathrm{SE}\right.$ ) and oviposition (mean number of egg-capsules per female $+\mathrm{SE}$ ) of infected and uninfected $H$. ulvae. A significant difference between infected and uninfected was found for both parameters. Penis size: Student $t$-test, $t_{36}=3.53, p=0.001$. Oviposition $(\ln [x+1]$ transformed data): Student $t$-test, $t_{55}=4.86, p<0.001$. The data analysis is based on poled size groups, since there was no significant correlation between initial size and either penis size or oviposition $(r<0.23, p>0.1)$.

primarily located in the gonads. Infected snails exhibited reduced penis size and oviposition rate in comparison with uninfected conspecifics (Fig. 1). Incomplete cessation of oviposition in infected snails was observed in eight specimens, of which six were infected by microphallide trematodes. The studied snails were known to be sexually mature as oviposition occurred early during the experiment among even the smallest female $H$. ulvae.

\subsubsection{Growth}

The specific growth rates of both infected and uninfected snails decreased with initial size, but parasitized specimens showed significantly higher growth rates than uninfected individuals (Fig. 2, Table 2). With an initial shell height of e.g. $4 \mathrm{~mm}$, a

Table 2

Analysis of covariance (specific growth rate versus initial shell height) of infected and uninfected $H$. ulvae

\begin{tabular}{lrlrr}
\hline Source of variation & df & Mean squares & $F$ & $P$ \\
\hline Zero slope & 1 & 1.25 & 191.59 & $<0.001$ \\
Effect of group & 1 & 0.49 & 74.86 & $<0.001$ \\
Residual & 91 & 0.01 & & \\
\hline
\end{tabular}

A preliminary full model ANCOVA showed that the two-way interaction effect was not significant $\left(F_{1,90}=0.90\right.$, $p=0.34$ ), indicating equality of slopes. Associated sum of squares and df are included in the residual variation in the present analysis. 


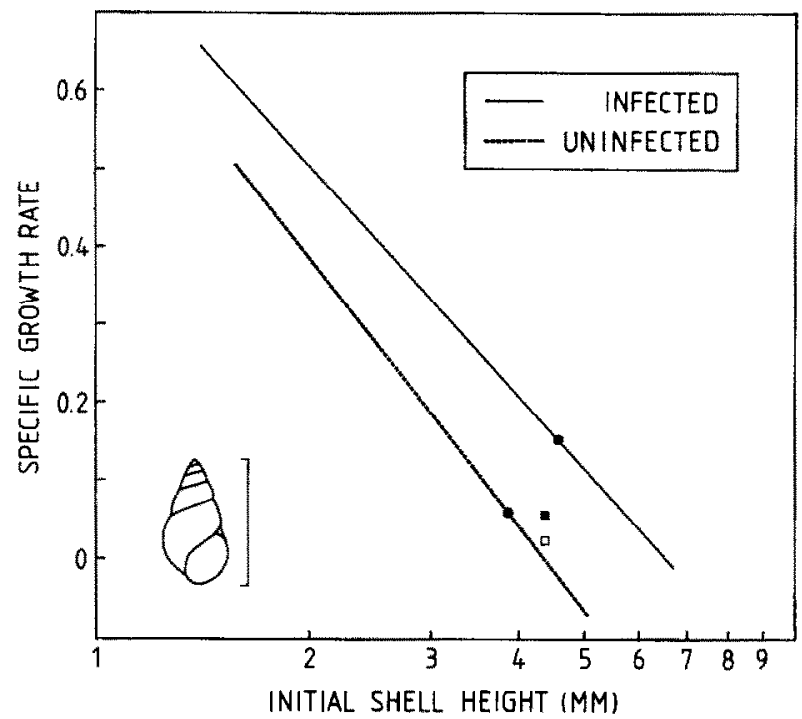

Fig. 2. Gompertz regressions of specific growth rate versus initial shell height for infected ( $Y=$ $\left.-0.430 \ln X+0.809 ; r^{2}=0.64, n=30, p<0.001\right)$ and uninfected $\left(Y=-0.494 \ln X+0.737 ; r^{2}=0.71, n=64\right.$, $p<0.001) H$. wlvae during a 6 week growth period. $\bullet$, grand means. The average specific growth rates observed among infected ( $\mathbf{})$ and uninfected (D) specimens from Experiment II are also given.

parasitized individual attained a $18 \%$ larger shell size than an uninfected conspecific at the end of the experiment. No significant interaction occurred among the growth curves within the analyzed size range $(1.4-6.7 \mathrm{~mm})$, indicating that infected $H$. ulvae reach a larger final size than uninfected specimens. Similar results were obtained by using wet weight instead of shell height as the independent variable (data not shown).

\subsubsection{Fgestion}

Total egestion by uninfected females and males as well as infected snails was positively correlated with the initial wet weight (Fig. 3). Uninfected females producing more than 40 egg-capsules exhibited higher egestion rates than uninfected males, whereas uninfected females producing less than 41 egg-capsules and parasitized specimens showed intermediate egestion rates (Fig. 3, Table 3). The difference between the two female groups reflects a significant positive relationship between total egestion and the number of egg-capsules produced ( $\left.Y=0.44 X+76.00 ; r^{2}=0.37, n=46, p=0.01\right)$.

The group of parasitized Hydrobia specimens showed the highest increase in egestion rate per size increment compared with the remaining categories (Fig. 3). Although this apparent slope heterogeneity is not significant at the default $5 \%$ level $(p=0.15$, Table 3), it is so at the $25 \%$ level recommended by Underwood (1981). This tendency of interaction due mainly to parasitized individuals is expected considering the difference in growth rates between infected and uninfected snails. For a given initial size, infected snails will always stay larger than their uninfected counterparts, and therefore produce more faeces. Hence, the difference in total egestion between uninfected females depositing more than 40 egg-capsules and infected snails may be larger than it appears. 


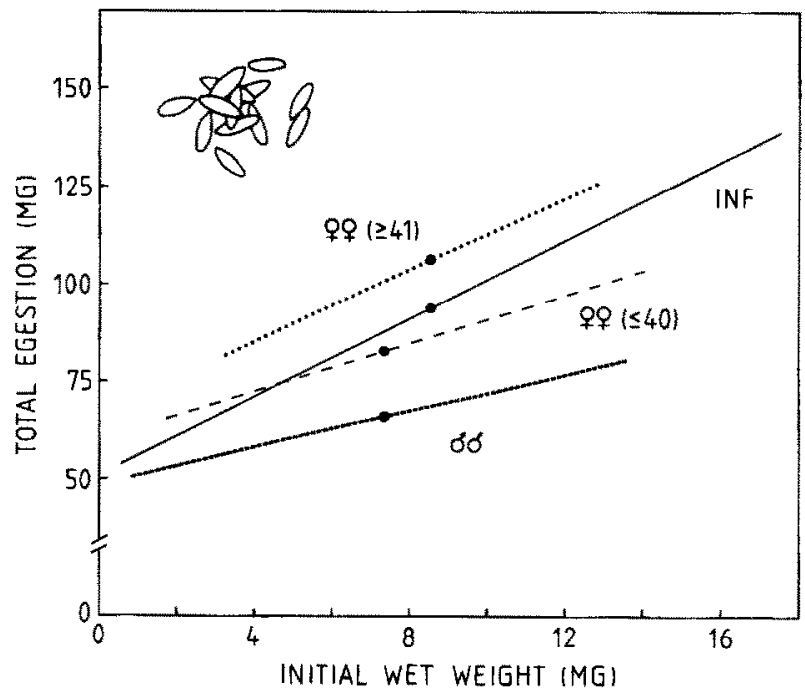

Fig. 3. Regressions showing total egestion versus initial wet weight for various groups of $H$. ulvae. Females depositing more than 40 egg-capsules $\left(Y=3.696 X+82.980 ; r^{2}=0.22, n=21, p=0.03\right)$, females depositing less than 41 egg-capsules $\left(Y=3.083 X+61.201 ; r^{2}=0.21, n=25, p=0.02\right)$, males $(Y=2.303 X+49.644$; $\left.r^{2}=0.31, n=18, p<0.017\right)$ and infected (INF) specimens $\left(Y=5.131 X+51.273 ; r^{2}=0.49 . n=30, p<0.001\right)$.

, grand means.

\subsection{Growth and $C / N$ content}

The results of the growth experiment with snails collected outside the reproductive season support the previous experiment in qualitative terms: parasitized snails obtained

Table 3

Analysis of covariance on the effect of initial wet weight on egestion among females depositing more than 40 egg-capsules, females depositing less than 41 egg-capsules, males and trematode infected $H$. whae from Experiment I

\begin{tabular}{lcccc}
\hline Source of variation & df & Mean squares & $F$ & $p$ \\
\hline Zero slope & 1 & 1.59 & 22.04 & $<0.001$ \\
Effect of group & 3 & 0.85 & 11.74 & $<0.001$ \\
Residual & 89 & 0.07 & & \\
& $+9(>40)$ & Infected & $+9(<41)$ & 63 \\
Adjusted means & 4.68 & 4.55 & 4.40 & 4.19 \\
Untransformed means $(\mathrm{mg})$ & 107.7 & 94.2 & 81.8 & 65.9 \\
A posteriori test & & & &
\end{tabular}

The Tukeys test with Kramers modification (Day \& Quinn, 1989) was used for the a posteriori comparison of adjusted mean faecal production. Underlines indicate values not significantly different $(p>0.05)$. A preliminary full model ANCOVA showed that the two-way interaction effect was not significant $\left(F_{3,86}=1.83\right.$, $p=0.15$ ), indicating equality of slopes. Associated sum of squares and df are included in the residual variation in the present analysis. The ANCOVA was performed on ln-transformed data. 
Table 4

$\mathrm{C} / \mathrm{N}$ composition and size of infected and uninfected $H$, ulvae from Experiment II

\begin{tabular}{lcccr}
\hline Parameter & Infected & Uninfected & No. of pairs & $p^{\mathrm{a}}$ \\
\hline Shell height $(\mathrm{mm})$ & $4.8+0.3$ & $4.6+0.3$ & $18^{\mathrm{b}}$ & $<0.01$ \\
C/N ratio $\left({ }^{\circ} /{ }_{0}^{\circ}\right)$ & $13.00 \pm 1.51$ & $12.54 \pm 1.96$ & $10^{\mathrm{b}}$ & 0.56 \\
Total N $(\mathrm{mol} / \mathrm{g})$ & $0.173 \pm 0.037$ & $0.184 \pm 0.038$ & $7^{\mathrm{b}}$ & 0.46 \\
Wet weight $(\mathrm{mg})$ & $1.14 \pm 0.21$ & $1.15 \pm 0.15$ & $7^{\mathrm{b}}$ & 0.82 \\
Dry weight $(\mathrm{mg})$ & $0.70 \pm 0.15$ & $0.74 \pm 0.09$ & $7^{\mathrm{b}}$ & 0.30
\end{tabular}

: Two-tailed signed rank test of the true $H_{0}$.

b Pairs of snails with similar initial shell height.

- Pairs of snails with similar terminal shell height.

Values are means $\pm \mathrm{SD}$.

a larger size than their uninfected conspecifics (Table 4). However, the difference in growth rates between the two snail groups was less during the present experiment than during Experiment I, despite twice the time for such a difference to evolve (Fig. 2). During Experiment II no oviposition occurred.

Of the 18 pairs of snails used in Experiment II, 10 showed within-pair discrepancies in shell height corresponding to or exceeding those required for detecting possible abnormal shell deposition among the infected specimens (see Materials and methods). Comparison of the $\mathrm{C} / \mathrm{N}$ ratio of infected and uninfected snails showed, however, no significant difference (Table 4). It is important to notice that no significant correlation existed between the $\mathrm{C} / \mathrm{N}$ ratio and the shell height, neither among infected nor uninfected individuals $\left(r_{\mathrm{s}}<0.40, n=10, p>0.1\right)$. Infected and uninfected snails that attained similar final shell height were also compared in pairs with respect to total $\mathrm{N}$ content, wet weight and dry weight. Neither of these characteristics differed significantly between the groups (Table 4).

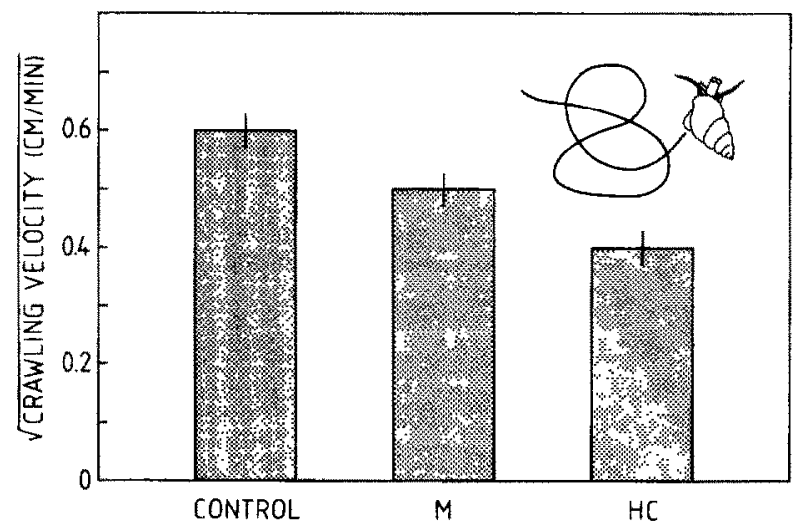

Fig. 4. The square-root transformed average erawling velocily $(\mathrm{cm} / \mathrm{min} \pm \mathrm{sE})$ of infected $(\mathrm{HC}=$ Himasthh continua infected; $\mathrm{M}=\mathrm{Microphallid}$ infected) and uninfected (CONTROL) $\mathrm{H}$. what during a $1.5 \mathrm{~h}$ observation period. A one-way ANOVA revealed significant differences among the mean values $\left(F_{2,119}=12.14\right.$, $p<0.001$ ). A posteriori tests (in SPSS) indicated that all three groups differed from each other $(p<0.05)$. 


\subsection{Locomotor activity}

The snails locomotor activity measured in terms of crawling velocity showed that infected snails moved significantly less (or slower) than uninfected specimens (Fig. 4). The results also indicate that snail mobility is more reduced during infections by echinostomide $(55 \%)$ than by microphallide trematodes $(31 \%)$, as judged by backtransformed mean values.

Among uninfected snails no significant sexual dichotomy regarding crawling velocity could be demonstrated on square-root transformed data (males: $0.61 \pm 0.21 \mathrm{~cm} / \mathrm{min}$ (mean \pm SD) females: $0.56 \pm 0.13$; Student $t$-test, $t_{36}=0.70, p=0.49$ ).

\section{Discussion}

The present results demonstrate that gigantism is evident in mature trematode infected H. ulvae as observed also by Rothschild \& Rothschild (1939). However, it is not obvious what the causal mechanism is. According to Cheng (1971), the observed difference in growth rate between infected and uninfected snails could simply be caused by an increased shell growth in infected specimens. A similar result was recorded by Joosse \& Van Elk (1986), showing that enhanced growth of infected snails only involved the shell and total body wet weight, whereas the tissue dry weight ultimately decreased. The greater body wet weight of infected specimens was attributed to a larger hemolymph volume. Compared with assimilation of dry matter, retainment of a higher hemolymph volume and especially abnormal calcification of the shell must be considered energetically cheap, and hence question a clear energetic connection between trematode infection and giant growth. If the present data are compatible with this scenario, the $\mathrm{C} / \mathrm{N}$ ratio would be expected to be higher in infected compared with uninfected Hydrobia from Experiment II. Furthermore, the total $\mathrm{N}$ content, body wet weight and body dry weight should be higher in uninfected than in infected snails that have attained similar shell height at the end of Experiment II. As none of these expectations were confirmed (Table 4), the mechanism suggested by Cheng (1971) and Joosse \& Van Elk (1986) seems not to provide an explanation of gigantism in $H$. ulvae. Parasite-induced erosion of the inner shell surface of the snail, as described by Davis \& Erasmus (1984), could theoretically increase the level of calcium carbonate in the hemolymph, and in turn, stimulate shell deposition at the mantle edge. This would increase the shell height without affecting the $\mathrm{C} / \mathrm{N}$ composition of the snail, hence invalidating the above conclusion. However, scanning electron microscopy of the inner shell surface of an uninfected $H$. ulvae and a specimen heavily infested with Himasthla continua, the most frequent trematode species in the experiments, indicated no difference between the two snails regarding such erosion (pers. obs.).

Accepting that gigantism in parasitized specimens most likely involved also somatic growth and therefor is basically an energetic question, the source of energy remains to be identified. Three not mutually exclusive possibilities seem to exist (1). Infected specimens increase food consumption in order to meet the energy demands of both parasite metabolism and increased growth. Evidence for increased as well as decreased 
feeding activity among infected individuals exists from other host-parasite associations (e.g. Meuleman, 1972; Williams \& Gilbertson, 1983). (2) Release of reproductive energy following parasitic castration is sufficient energy supply for both parasites and excess growth. It follows that the energetic cost of parasites is less than the snails own offspring. This is the most generally accepted mechanism (Rothschild, 1936; McClelland \& Bourns, 1969; Wilson \& Denison, 1980; Sousa, 1983) supported especially by the study of Bourns (1974), showing that the cost in terms of carbohydrate and protein content of eggs of Lymnaea stagnalis was higher than that of cercariae produced during the same period of time. (3) Because a substantial part of a snail's energy budget is allocated to the expense of crawling (about $80 \%$ in Biomphalaria glabrata), reduced locomotor activity could off-set any energy deficit imposed by a discrepancy between ingestion and the demands of parasites and increased growth (Becker, 1980a,b).

Considering egestion rate as an appropriate equivalent to consumption, there is no evidence for increased consumption among infected $H y d r o b i a$ specimens. The egestion rate of infected snails was close to uninfected males, and certainly lower than the most fecund females (Fig. 3). In contrast, the almost complete castration of parasitized Hydrobia brings support for the second possibility, suggesting release of reproductive energy as the decisive energy supply. Whether this frees enough resources for both parasite and excess host growth is, however, questionable. In H. ulvae, a substantial additional energy pool appears to originate also from reduced locomotor activity. If $80 \%$ of Hydrobia's energy budget as in B. glabrata is allocated to the expense of crawling, the observed $30-55 \%$ reduction in movement in infected $H y d r o b i a$ specimens is a considerable saving of energy. Because of no serious decrease in feeding, this energy pool can be allocated uncut to parasites and/or additional growth.

The growth rate of the snails was higher during Experiment I using reproducing specimens than during Experiment II where no oviposition occurred. This discrepancy is difficult to interpret because of differences in experimental treatment and design. However, since the snails from Experiment II did not show oviposition, relatively less energy might have been allocated to the gonads and mate searching, and a parasitic castration would hence release comparatively less energy for additional growth.

Although gigantism occurs among snails in the laboratory, it is not necessarily evident in the field. According to Fernandez \& Esch (1991a) gigantism is most probably a laboratory artefact caused by providing the snails with ad libitum food. In support of this idea, they argue that (1) three studies using mark-recapture experiments in the field failed to show gigantism in infected specimens, (2) snails in nature usually subsist under competitive conditions leaving no energy free for additional growth, (3) laboratory studies investigating the same host-parasite systems have reached contradictive conclusions. Some of the difficulties in obtaining a clear picture may well originate from the variety of laboratory setups applied when gigantism has been studied. However, we belicve that the present results can be extrapolated to the field for the following reasons: (1) the growth rates observed in the laboratory (Experiment I) correspond to growth rates recorded in situ (Jensen, 1980); (2) it is questionable whether food is a limiting factor for hydrobiids inhabiting intertidal flats, at least outside the winter season (e.g. Wiltse et al., 1984); (3) H. ulvae is actively feeding on the sediment surface in situ both by day and by night as well as during low tide (pers. obs.), suggesting that 
the laboratory condition enabling $24 \mathrm{~h}$ feeding opportunities is realistic; (4) the fecundity in terms of egg-capsules of uninfected females in the laboratory is below values observed under approximated field conditions (e.g. Lassen \& Clark, 1979). This would not be expected if the snails had optimal feeding conditions in the laboratory, considering the observed positive relationship between egestion rate and oviposition.

According to Sousa (1983), gigantism should almost exclusively evolve in mature short-lived semelparous species. Generally, such species invest high amounts of energy in early "big bang" reproduction, and if castrated there might be enough energy for both parasites and additional host growth. Longer-lived iteroparous snails, in contrast, allocate less energy to reproduction on an annual base. However, this hypothesis has proven not to be entirely consistent by virtue of the absence of gigantism in the semelparous snail Helisoma anceps (Fernandez \& Esch, 1991a). Another approach was adopted by Minchella (1985) who considered increased growth rates in infected specimens as a host adaptation directing energy from parasites into growth. Because fecundity is generally positively related to size (Browne \& Russell-Hunter, 1978), the host would benefit from an increased growth rate if the infection was lost later. In the long run, this would compensate for the lost reproduction during infection. In contrast to Sousa, Minchella predicts gigantism to be expressed in longer-lived, and thus, usually iteroparous species with a high expectation of surviving more than one reproductive period. Interestingly, both Sousa and Minchella refer to gigantism in $H$. ulvae as supportive for their conflicting hypotheses. Sousa considers H. ulvae a short-lived semelparous species, whereas Minchella considers it a longer-lived iteroparous species. Both authors may be correct. In a comparative study of an intertidal and a lagoonal population of $I$. ulvae, Barnes (1990) showed that the two populations had different lifc histories, the intertidal one being semelparous and the lagoonal one being more or less iteroparous. The life-history traits of $H$. ulvae inhabiting Højer tidal flat have not yet undergone detailed study, but it is known that a part of the population manages to survive two breeding seasons (pers. obs.). Whether this should reject Sousa's hypothesis is a matter of discussion, depending on a strict or relaxed definition of semelparity. Nevertheless, the hypothesis proposed by Minchella necessitates that the hosts are able to lose their infection, for which there is only little evidence (Rothschild, 1942; Sousa, 1983; but sce Goater et al., 1989; Fernandez \& Esch, 1991b). In addition. natural selection should have favoured the development of a specific mechanism able to direct energy from the infected gonads into growth. It is difficult to envisage how such a mechanism can spread through the population unless snail fecundity after loss of parasites is unrealistically high (sensu Cole, 1954; Browne \& Russell-Hunter, 1978; Stearns, 1992). In stead, it seems that snails exposed to a high risk of infection turn toward earlier maturation as a possible way of avoiding the negative impact of parasitic castration (Lafferty, 1993).

We doubt that giant growth is a consequence of host adaptation, and expect the phenomenon merely to be a matter of default reallocation of energy as a consequence of parasitic castration. The amount of energy available for parasites and host growth following castration may depend on the life history of the host, the amount of locomotion unrelated to feeding, the amount of food accessible to the host, as well as the competitive conditions the hosts experience in their habitats. Since these factors may 
vary between localities or seasons (e.g. Underwood, 1984; Wiltse et al., 1984, Barnes, 1990), gigantism can not be expected to be entirely species specific, and should therefore be studied at the level of subpopulations, both during and outside the snails' reproductive season. The general lack of consensus on the phenomenon could in part be accounted for by such usually unaddressed variables.

\section{Acknowledgements}

We are in dept to Professor T.H. Blackburn for access to the $\mathrm{C} / \mathrm{N}$ analyser, and wish to thank P. Jensen, A. Jensen, A. Sølling and M. Carlsen for technical assistance. The study was supported by the Carlsberg Foundation (K.N. Mouritsen).

\section{References}

Barnes, R.S.K., 1990. Reproductive strategies in contrasting populations of the coastal gastropod Hydrobia ulvae. II. Longevity and life-time egg production. J. Exp. Mar. Biol. Ecol., Vol. 138, pp. 183-200.

Becker. W., 1980a. Metabolic interrelationship of parasitic trematodes and molluscs, especially Schistosoma mansoni in Biomphalaria glabrata. Z. Parasitenkd., Vol. 63, pp. 101-111.

Becker, W., 1980b. Microcalorimetric studies in Biomphalaria glabrata: The influence of Schistosoma mansom on the basal metabolism. J. Comp. Physiol. B, Vol. 135, pp. 101-111.

Bourns. T.K.R., 1974. Carbohydrate and protein in Lymnaea stagnalis eggs and Trichobilharzia ocellata cercariac. J. Parasitol., Vol. 60, pp. 1046-1047.

Browne, R.A. \& W.D. Russell-Hunter, 1978. Reproductive effort in molluscs. Oecologia. Vol. 37, pp. 2327.

Cheng, T.C., 1971. Enhanced growth as a manifestation of parasitism and shell depositing in parasitized molluscs. In, Aspects of the biology of symbiosis, edited by T.C. Cheng, University Park Press, Baltimore, pp. $103-137$.

Cole, L.C. 1954. The population consequences of life history phenomena. Q. Rev. Biol., Vol. 29, pp. 103137.

Crews, A.E. \& T.P. Yoshino, 1989. Schistosoma mansoni: effect of infection on reproduction and gonadal growth in Biomphalaria glabrata. Exp. Parasitol., Vol. 68, pp. 326-334.

Curtis, L.A. \& K.M. Hubbard, 1990. Trematode infections in a gastropod host misrepresented by observing shed cercariae. J. Exp. Mar. Biol. Ecol., Vol. 143, pp. 131-137.

Davis, T.W. \& D.A. Erasmus, 1984. An ultrastructural study of the effect of parasitism by larval Schistosoma mansoni on the calcium reserves of the host, Biomphalaria glabrata. Cell Tissue Res., Vol. 236. pp. 643-649.

Day, R.W. \& G.P. Quinn, 1989. Comparisons of treatments after an analysis of variance in ecology. Ecol. Monogr., Vol. 59, pp. 433-463.

Deblock, S., 1980. Inventaire des trématodes larvaires parasites des mollusques Hydrobia (prosobranches) des côtes de France. Parassitologia, Vol. 22, pp. 1-105.

Fernandez, J. \& G.W. Esch, 1991 a. Effect de parasitism on the growth rate of the pulmonate snail Helisoma anceps. J. Parasitol., Vol. 77, pp. 937-944.

Fernandez, J.\& G.W. Esch, 1991b. Guild structure of larval trematodes in the snail Helisoma anceps: patterns and processes at the individual host level. J. Parasitol., Vol. 77, pp. 528-539.

Goater, T.M., A.W. Shostak, J.A. Williams \& G.W. Esch, 1989. A mark-recapture study of trematode parasitism in overwintered Helisoma anceps (pulmonata), with special reference to Halipegus orridualis (Hemiuridae). J. Parasitol., Vol. 75, pp. 553-560.

Hull, C.H. \& N.H. Nie, 1981. SPSS update 7-9. McGraw-Hill Book Company, New York, 402 pp.

Huxham, M., D. Raffaelli \& A. Pike, 1993. The influence of Cryptocotyle lingua (Digenea:Platyhelminthes) 
infections on the survival and fecundity of Littorina littorea (Gastropoda:Prosobranchia); an ecological approach. J. Exp. Mar. Biol. Ecol., Vol. 168, pp. 223-238.

Jensen, K.T., 1980. Aspekter af Hydrobia ulvae's og Corophium volutator's økologi i vadchavet. Thesis, University of Århus, Denmark, 121 pp.

Jensen, K.T. \& K.N. Mouritsen, 1992. Mass mortality in two common soft-bottom invertebrates, Hydrobia ulvae and Corophium volutator - the possible role of trematodes. Helgol. Meersunters., Vol. pp. 329-339.

Jensen, K.T. \& H.R. Siegismund, 1980. The importance of diatoms and bacteria in the diet of Hydrobiaspecies. Ophelia, Suppl. 1, pp. 193-199.

Joosse, J. \& R. Van Elk, 1986. Trichobilharzia ocellata: physiological characterization of giant growth, glycogen depletion, and absence of reproductive activity in the intermediate snail host, Lymnaea stagnalis. Exp. Parasitol., Vol. 62, pp. 1-13.

Kaufmann, K.W., 1981. Fitting and using growth curves. Oecologia, Vol. 49, pp. 293-299.

Lafferty, K.D., 1993. The marine snail, Cerithidea californica, matures at smaller sizes where parasitism is high. Oikos, Vol. 68, pp. 3-11.

Lassen, H.H. \& M.E. Clark, 1979. Comparative fecundity in three danish mudsnails (Hydrobiidae). Ophelia Vol. 18 , pp. 171-178.

McClelland, G. \& T.K.R. Bourns, 1969. Effects of Trichobilharzia ocellata on growth, reproduction, and survival of Lymnaea stagnalis. Exp. Parasitol, Vol. 24, pp. 137-146.

Meuleman, E.A., 1972. Host-parasite interrelationships between the freshwater pulmonate Biomphalaria pfeifferi and the trematode Schistosoma mansoni. Neth. J. Zool., Vol. 22, pp. 355-427.

Minchella, D.J., 1985. Host life-history variation in response to parasitism. Parasitol., Vol 90, pp. 205216.

Moose, J.W., 1963. Growth inhibition of young Oncomelania nosophora exposed to Schistosoma japonicum. J. Parasitol. Vol. 49, pp. 151-152.

Rothschild, M.. 1936. Gigantism and variation in Peringia ulvae Pennant 1777, caused by infection with larval trematodes. J. Mar Biol. Assoc. U.K., Vol. 20, pp. 537-546.

Rothschild. M., 1942. A seven-year-old infection of Cryptocotyle lingua Creplin in the periwinkle Littorina littorea L. J. Parasitol., Vol. 28, pp. 350.

Rothschild, A. \& M. Rothschild. 1939. Some observations on the growth of Peringia ulvae (Pennant) 1777 in the laboratory. Novit. Zool., Vol. 41, pp. 240-247.

Sluiters, J.F., C.M. Brussaard-Wüst \& E.A. Meuleman, 1980. The relationship between miracidial dose, production of cercariae, and reproductive activity of the host in the combination Trichobilharzia ocellata and Lymnaea stagnalis. Z. Parasitenkd., Vol. 63, pp. 13-26.

Sousa, W.P., 1983. Host life history and the effect of parasitic castration of growth: a field study of Cerithidea californica Haldemann (gastropoda:prosobranchia) and its trematode parasites. J. Exp. Mar. Biol. Ecol.. Vol. 73, pp. 273-296.

Stearns, S.C., 1992. The evolution of life histories. Oxford University Press, Oxford, $249 \mathrm{pp}$.

Sturrock. B.M. \& R.F. Sturrock. 1970. Laboratory studies of the host-parasite relationship of Schistosoma mansoni and Biomphalaria glabrata from St. Lucia, West Indies. Ann. Trop. Med. Parasitol., Vol. 64, pp. 357-363.

Underwood, A.J., 1981. Techniques of analysis of variance in experimental marine biology and ecology. Oceanogr. Mar. Biol. Annu. Rev., Vol. 19, pp. 513-605.

Underwood, A.J., 1984. Vertical and seasonal patterns in competition for microalgae between intertidal gastropods. Oecologia, Vol. 64, pp. 211-222.

Wesenberg-Lund, C.J., 1934. Contribution to the development of the trematode digenea. Part II. The biology of the freshwater cercariae in Danish freshwaters. D. Kgl. Danske Vidensk. Selsk. Skrifter, Vol. 5 , pp. $1-223$.

Williams, C.L. \& Gilbertson, D.E., 1983. Altered feeding response as a cause for the altered heartbeat rate and locomotor activity of Schistosoma mansoni-infected Biomphalaria glabrata. J. Parasitol., Vol. 69, pp. 671-676.

Wilson, R.A. \& J. Denison, 1980 . The parasitic eastration and gigantism of Lymnaea truncanta infected with the larval stages of Fasciola hepatica. Z. Parasitenkd. Vol. 61, pp. 109-119.

Wiltse, W.I., K.H. Foremann, J.M. Teal \& I. Valiela, 1984. Effects of predators and food resources on the macrobenthos of salt marsh creeks. J. Mar. Res., Vol. 42, pp. 923-942. 